\title{
METODĂ NOUĂ DE APRECIERE A TOXICITĂŢII SUBSTANTYELOR CHIMICE
}

\author{
Toderaș Ion', Gulea Aurelian², Gudumac Valentin², \\ Roșcov Elena ${ }^{2}$, Garbuz Olga ${ }^{2}$
}

${ }^{1}$ Academia de Știinţe a Moldovei, Institutul de Zoologie, Chișinău, Moldova, iontoderas@yahoo.com

2Universitatea de Stat din Moldova, Chișinău, Moldova, guleaaurelian@gmail.com, elena.arcan@gmail.com, olhamos@mail.ru

3Universitatea de Stat de Medicină și Farmacie "Nicolae Testemițanu" din Republica

Moldova, Chișinău, Moldova, valentin.gudumac@usmf.md

https://doi.org/10.53937/9789975315975.81

\begin{abstract}
We developed a new invention that relates to method for assessing the toxicity of chemical substances.The method of the invention includes the preparation of the culture of Paramecium caudatum, adding to the samples investigated to test chemicals in various concentrations, incubating the sample to be studied and control the addition of colourant 3-amino-7-dimethylamino-2-methylphenazine hydrochloride, incubation with subsequent addition of solution of formalin, centrifuging the sample, removing the supernatant, adding the solution of hydroxide of sodium, determine the absorbance using a spectrophotometer, followed by calculating the percentage of paramecii viability and determine the lethal concentration $\left(L C_{50}\right)$ at the same time as the value of the concentration $L C_{50}$ is small, the toxicity of the tested substance is higher.
\end{abstract}

Key words: Paramecium caudatum, chemical substances, colourant 3-amino-7-dimethylamino-2-methylphenazine hydrochloride, lethal concentration $\left(L C_{50}\right)$, spectrophotometer.

\section{INTRODUCERE}

O serie de substanţe chimice, înainte de a fi utilizate în alte domenii (ex: farmacologie), trebuie testate din punct de vedere al toxicităţii. Studiile de toxicitate experimentală se clasifică în mai multe grupe: a toxicităţii acute și subacute; a efectelor mutagene; a toxicităţii pe termen 
lung și a efectelor asupra reproducţiei și de ecotoxicitate Milhaud et al., (1995) [2].

Toxicitatea acută exprimă efectele nefaste care se manifestă într-o perioadă dată după administrarea unei doze unice de substanță. Indicatorul cel mai utilizat pentru aprecierea toxicității acute este concentrația letală 50 \% ( $\left(\mathrm{LC}_{50}\right)$. $\mathrm{LC}_{50}$ reprezintă concentrația unei substanțe, calculată statistic, care provoacă, după expunerea pentru o perioadă definită, moartea a $50 \%$ dintre animale într-un interval de timp determinat.

În studiile de toxicitate se utilizează cel mai frecvent animalele de laborator. Tendința de limitare a experimentelor pe animale a dus la dezvoltarea unor "metode alternative" de testare a toxicității pe culturi de celule.

Testele de ecotoxicitate directă - constau în urmărirea efectului produsului de testat asupra unei singure specii, întreținută într-un biotop simplificat (artificial). Cel mai frecvent se utilizează organisme acvatice: alge, ciliate, purici de baltă (Daphnia magna). Cele mai sensibile sunt ciliatele Paramecium caudatum [5]. Aceste organisme unicelulare includ animale care constau dintr-o singură celulă și sunt, în același timp, întregul organism, care se caracterizează prin toate semnele vitale: metabolism, creștere și dezvoltare, reproducere, iritabilitate, viabilitate. Iritabilitatea înseamnă capacitatea unui organism viu de a răspunde la acţiunea diverșilor factori ai mediului [1]. În conformitate cu diverse condiții de viață acest indice se manifestă diferit la diferite animale.

În ultima perioadă se atestă o tendință de a utiliza organismele unicelulare ca obiecte model pentru cercetare, dezvoltarea metodelor rapide de evaluare a eficacității medicamentelor și a acțiunii substanțelor toxice. Prin urmare, studiul de iritabilitate, adaptibilitate și viabilitate atunci când test-obiectele sunt expuse la acţiunea diferitelor substanțe chimice sunt unele dintre problemele biologiei moderne.

O atenție specială s-a acordat cercetărilor care furnizează informații despre nivelul de toxicitate al unor compuși chimici și influența acestora 
asupra potențialului de creștere a populațiilor de ciliate, contribuind la stabilirea dozelor toxice după metoda nouă brevetată "Metodă de apreciere a toxicităţii substanţelor chimice", Toderaș I., ș.a. [4].

\section{MATERIALE ȘI METODE}

Sunt cunoscute metode clasice de determinare a toxicităţii substanţelor chimice, care constau în cultivarea periodică și neîntreruptă a infuzoriilor Pammecium caudatum pentru determinarea ritmului de dividere în dependenţă de hrană și temperatură [6]. Neajunsul acestei metode constă în perioada mare de timp (până la 14 zile) necesară pentru realizarea ei, factorul timpului având un rol decisiv în realizarea metodei indicate.

Mai este cunoscută metoda care prevede determinarea toxicităţii substanţelor chimice din mediul acvatic în care în calitate de test-cultură sunt utilizate infuzoriile Paramecium caudatum, toxicitatea substanţelor chimice fiind evaluată după gradul de reducere a activităţii locomotorice în raport cu activitatea locomotoare în proba iniţială (de control) [3]. Dezavantajul acestei metode constă în complexitatea și durata mare de timp (96 ore) cheltuit la realizarea ei, sensibilitatea și precizia nesatisfăcatoare.

Problema pe care o rezolvă invenţia constă în elaborarea și optimizarea condiţiilor de efectuare a metodei de apreciere a toxicităţii substanţelor chimice cu utilizarea organismelor monocelulare, în special a infuzoriei $P$. caudatum, marirea sensibilităţii, reproductibilităţii și a preciziei metodei, reducerea cheltuielilor la realizarea acesteia, posibilitatea procesării probelor în serie cu un efect economic substanţial.

Metoda se efectuează în modul următor. Se pregătește cultura-start, pentru aceasta se selectează, cu ajutorul microcapilarului, celule de Paramecium caudatum și se transferă în microcosme cu mediu nutritiv ce conţine suspensia de drojdii de panificaţie Saccharomyces cerevisiae cu concentraţia de $1 \mathrm{~g}$ (masă uscată) de drojdii la un litru de apă de robinet declorată. Cultura-start de Paramecium caudatum se ţine 2-3 zile în termostat la o temperatură constantă de $23^{\circ} \mathrm{C}$, timp în care se produce 
înmulţirea parameciilor, după care resturile metabolice se înlătură prin filtrare, se numără celulele de $P$. caudatum și se aduce numărul lor cu apă de la robinet declorată până la circa $3,0 \times 10^{3} / \mathrm{mL}$ celule, apoi se pregătesc probele de cercetat, pentru aceasta cultura de $P$. caudatum se pipetează în tuburi Eppendorf câte $890 \mu \mathrm{L}$ de cultură, se adaugă diluţiile substanţelor testate, fiecare probă se repetă de cel puţin 3 ori (în triplet).

La fel se montează în triplet și probele de control (conţin cultură de $P$. caudatum fără substanţele testate), apoi toate probele se incubează într-un loc întunecat la temperatura camerei timp de 24 ore. În timpul incubării se efectuează evaluarea microscopică a probelor testate și se analizează: dezvoltarea parameciilor, comportamentul, morfologia, formarea chisturilor. La formarea chisturilor se constată modificările survenite, fără a se face măsurări suplimentare. După 24 ore în toate probele se adăugă câte $100 \mu \mathrm{L}$ de soluţie de colorant 3-amino-7-dimetilamino-2- metilfenazin clorhidrat (Roșu neutru, NR) cu concentraţia de $60 \mathrm{mg} / \mathrm{mL}$, probele se agită și se incubează într-un loc întunecat la temperatura camerei timp de 3-4 ore. După aceasta în toate probele se adaugă câte $10 \mu \mathrm{L}$ de soluţie de formalină de 0,4\% și se agită atent, după 2-3 min probele se centrifughează timp de 5 min la 2000 turaţii, apoi supematantul se înlătură atent, fără tulburarea sedimentului. Imediat sedimentul se resuspendează în $1 \mathrm{~mL}$ de apă de robinet și se centrifughează, spălarea sedimentului cu centrifugare se repetă până la decolorarea supernatantului, după care sedimentul se amestecă cu $110 \mu \mathrm{L}$ de soluţie de $3 \mathrm{M}$ de $\mathrm{NaOH}$ până la obţinerea unei soluţii omogene. Apoi, se transferă câte $100 \mu \mathrm{L}$ de soluţie din fiecare tub Eppendorf în godeurile microplăcii fotometrice cu 96 de godeuri a unui spectofotometru și se măsoară absorbanţa (densitatea optică) la lungimile de undă de 540 nm și 690 nm, după care se calculează procentul de paramecii vii utilizând formula:

\% paramecii vii $=\left(\left(\mathrm{Abs}_{540 \mathrm{pr}}-\mathrm{Abs}_{690 \mathrm{pr}}\right)\right) /\left(\left(\mathrm{Abs}_{540 \mathrm{k}}-\mathrm{Abs}_{690 \mathrm{k}}\right)\right) \times 100$, unde:

$\mathrm{Abs}_{540 \mathrm{pr}}$ si $\mathrm{Abs}_{690 \mathrm{pr}}$-valoarea absorbanţei probei de cercetat la lungimile de undă de 540 și 690 nm; 
$\mathrm{Abs}_{540 \mathrm{k}}$ și $\mathrm{Abs}_{690 \mathrm{k}}$-valoarea absorbanţei probei de control la lungimile de undă de 540 și 690 nm,

și se determină concentraţia letală $\left(\mathrm{LC}_{50}\right)$, totodată, cu cât valoarea concentraţiei $L_{50}$ este mai mică, cu atât toxicitatea substanţei chimice testate este mai mare.

Astfel, metoda prezentată constă în accelerarea testării substanţelor toxice cu utilizarea organismelor monocelulare Paramecium caudatum și a colorantului Roșu neutru, creșterea sensibilităţii, reproductibilităţii și a preciziei metodei, posibilitatea procesării probelor în serie, reducerea cheltuielilor la realizarea metodei cu obţinerea unui efect economic substanţial. Metoda este mai sensibilă, mai ieftină, mai specifică, iar reactivii folosiţi sunt stabili și, totodată, metoda propusă prezintă mai puţine interferenţe. Metoda se referă la biologie și toxicologie, și anume la metode de apreciere a toxicităţii substanţelor chimice. De exemplu, ca material de cercetare a fost luată substanţa CMT-67 și în calitate de etalon a fost utilizată substanţa $\mathrm{Cu}\left(\mathrm{NO}_{3}\right)_{2}$ în diapazonul concentraţiilor 100-1 $\mu \mathrm{M}$.

\section{REZULTATE ȘI DISCUŢII}

Conform metodei descrise în articolul dat au fost efectuate cercetări de determinare a toxicităţii substanţelor $\mathrm{CMT}-67$ și $\mathrm{Cu}\left(\mathrm{NO}_{3}\right)_{2}$ în Laboratorul Sistematică și Filogenie Moleculară al Institutului de Zoologie.

Substanţele chimice au fost testate la concentraţiile de 100, 10 și 1 $\mu \mathrm{M}$, incubate la temperatura camerei de $25^{\circ} \mathrm{C}$ timp de 24 și $48 \mathrm{~h}$. A fost calculată viabilitatea celulelor în corelaţie cu concentraţiile utilizate și, astfel, a fost posibil de determinat indicele toxic $L C_{50}$. Totodată, cu cât este mai mic procentul de paramecii vii, cu atât toxicitatea substanţelor cercetate este mai mare. În timpul incubării s-a efectuat evaluarea microscopică a probelor testate: dezvoltarea parameciilor, comportamentul, activitatea locomotorică, formarea chisturilor. 
Tabelul 1: Rezultatele acţiunii compusului testat CMT-67 asupra culturii de Paramecium caudatum după 24 şi 48 ore

\begin{tabular}{|c|c|c|c|c|c|c|c|c|c|}
\hline COD & $\begin{array}{c}\text { Concentrația } \\
\mu \mathrm{M}\end{array}$ & $\begin{array}{l}\text { Viabilitatea } \\
(\%), 24 \text { ore }\end{array}$ & $\begin{array}{l}\text { SD } \\
(\%)\end{array}$ & $\begin{array}{l}\mathrm{LC} 50 \\
\mu \mathrm{M}\end{array}$ & $\begin{array}{l}S D \\
\mu M\end{array}$ & $\begin{array}{l}\text { Viabilitatea } \\
(\%), 48 \text { ore }\end{array}$ & $\begin{array}{l}\text { SD } \\
(\%)\end{array}$ & $\begin{array}{c}\mathrm{LC} 50 \\
\mu \mathrm{M}\end{array}$ & $\mathrm{SD} \mu \mathrm{M}$ \\
\hline \multirow[t]{3}{*}{ CMT-67 } & 100 & 0 (chisturi) & & \multirow[t]{3}{*}{10,0} & \multirow[t]{3}{*}{0,2} & 0 (chisturi) & & \multirow[t]{3}{*}{5,1} & \multirow[t]{3}{*}{1,6} \\
\hline & 10 & 50,7 & 3,0 & & & 40,5 & 4,3 & & \\
\hline & 1 & 103,0 & 2,8 & & & 76,2 & 6,0 & & \\
\hline
\end{tabular}

Notă: sunt prezentate valorile medii ale absorbanţei a 3 determinări paralele.

La acţiunea compusului CMT-67, la concentraţia de $1 \mu \mathrm{M}$ de substanţă celulele aveau o formă regulată a corpului, miscarea era relativ haotică, fără a se opri din mișcare. Viabilitatea parameciilor după 24 ore a constituit 103\%, comparativ cu martorul. După 48 de ore indicele viabilității s-a micșorat până la 76,2 \%.

La concentraţia de $10 \mu \mathrm{M}$ a preparatului, mișcările parameciilor au fost mai încetinite și circulare. Evaluarea microscopică a semnalat lezarea celulelor (Fig. 2,C), viabilitatea după 24 ore a fost de 50,7 \%, iar după 48 de ore - de 40,5\% în comparaţie cu lotul martor.
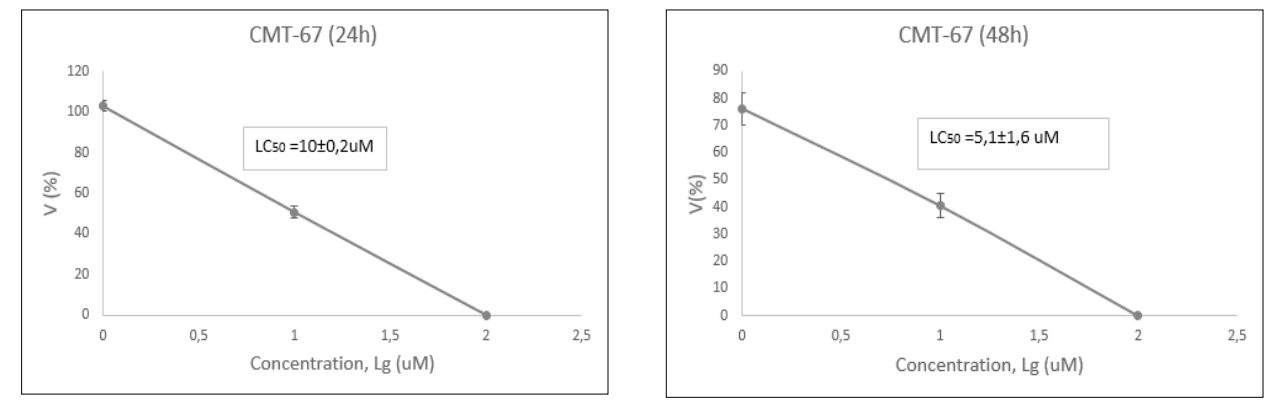

Figura 1. Viabilitatea populaţiei Paramecium caudatum la acţiunea compusului CMT-67 după 24 şi 48 ore de acţiune.

La acţiunea a $100 \mu \mathrm{M}$ de concentraţie a avut loc remodelarea celulelor de parameciu: o parte dintre celule se umflau, capătând o formă sferică, clar pronunţată astfel s-a produs închistarea organismelor (mod de protecţie a ciliatelor la acţiunea factorilor nefavorabili de trai, (Fig.2, A). La alte celule peretele celular se distrugea și ducea la moartea acestora 
(Fig.2, B). La formarea chisturilor se constată modificările survenite, fără a se face măsurări suplimentare. După 24 ore de incubare indicele toxic $L C_{50}$ $=10,0 \pm 0,2 \mu \mathrm{M}$, iar după 48 de ore $\mathrm{LC}_{50}-5,1 \pm 1,6 \mu \mathrm{M}$ (Tab.1).

Activitatea substanţei CMT-67 continua s-ă scadă pe toată perioada tes-

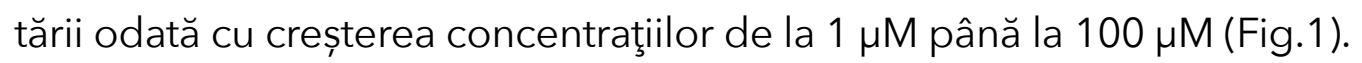
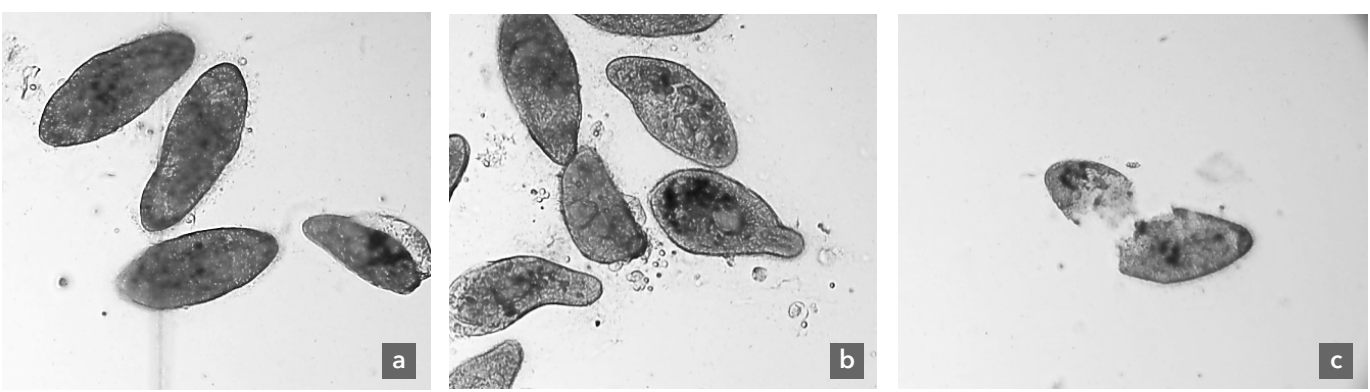

Figura 2. Activitatea substanţelor $\mathrm{CMT}-67$ şi $\mathrm{Cu}\left(\mathrm{NO}_{3}\right)_{2}$ asupra test-culturei de paramecii. A - Închistarea celulelor; B - Închistarea şi lezarea celulelor; C - Lezarea celulelor.

În continuare a fost demonstrată activitatea compusului $\mathrm{Cu}\left(\mathrm{NO}_{3}\right)_{2}$ la concentraţiile de 100, 10 și $1 \mu \mathrm{M}$. Viabilitatea la concentraţa de $1 \mu \mathrm{M}$ după 24 de ore de administrare, este de 95,9\%, iar după 48 de ore se impune o scădere de 76,2 \%, comparativ cu martorul. La acţiunea concentraţ̧iei de $10 \mu \mathrm{M}$ procentul viabilităţii este între 34,1 și 30,4 \% timp de 24 și respective 48 ore, iar la concentraţia de $100 \mu \mathrm{M}$ se atestă modificări a indecelui dat cu valorile cuprinse între 20,9 și 1,2% (Tab.2).

Tabelul 2: Rezultatele acţiunii compusului testat $\mathrm{Cu}(\mathrm{NO}) 2$ asupra culturii de Paramecium caudatum după 24 şi 48 ore

\begin{tabular}{|c|c|c|c|c|c|c|c|c|c|}
\hline COD & $\begin{array}{c}\text { Concentrația } \\
\mu \mathrm{M}\end{array}$ & $\begin{array}{c}\text { Viabilita- } \\
\text { tea } \\
(\%), 24 \text { ore }\end{array}$ & $\begin{array}{l}\text { SD } \\
\text { (\%) }\end{array}$ & $\begin{array}{c}\mathrm{LC} 50 \\
\mu \mathrm{M}\end{array}$ & $\begin{array}{l}S D \\
\mu M\end{array}$ & $\begin{array}{l}\text { Viabilitatea } \\
\text { (\%), } 48 \text { ore }\end{array}$ & $\begin{array}{l}\text { SD } \\
\text { (\%) }\end{array}$ & $\begin{array}{c}\text { LC50 } \\
\mu \mathrm{M}\end{array}$ & $\begin{array}{l}S D \\
\mu \mathrm{M}\end{array}$ \\
\hline \multirow{3}{*}{$\mathrm{Cu}(\mathrm{NO} 3) 2$} & 100 & 20,9 & 6,3 & \multirow{3}{*}{7,2} & \multirow{3}{*}{1,9} & 1,2 & 0,8 & \multirow{3}{*}{4,2} & \multirow{3}{*}{0,1} \\
\hline & 10 & 30,4 & 8,1 & & & 34,1 & 1,9 & & \\
\hline & 1 & 95,9 & 4,8 & & & 76,2 & 2,7 & & \\
\hline
\end{tabular}

Notă: sunt prezentate valorile medii ale absorbanţei la 3 determinări paralele. 
La evaluarea microsopică a probelor testate, la concentraţiile de 100 și $10 \mu \mathrm{M}$ s-au constatat modificări ale deplasării organismelor studiate, inclusiv mișcări haotice, circulare a celulelor, cu o formă regulată a corpului, iar la unele lezarea peretelui celular a dus la moartea organismelor (Fig.2, C). La concentraţia de $1 \mu \mathrm{M}$ s-a observat modificări ale viabilităţii abia după 48 ore de administrare, acest indice fiind cu 23,8 \% mai mic decât la lotul control.

Concentraţia toxică letală $50 \%$ la acţiunea substanţei $\mathrm{Cu}\left(\mathrm{NO}_{3}\right)_{2}$ după 24 ore este $\mathrm{LC}_{50}=7,2 \pm 1,9 \mu \mathrm{M}$, iar după 48 de ore $\mathrm{LC}_{50}$ este de $4,2 \pm 0,1$ $\mu \mathrm{M}$. Astfel, toxicitatea preparatului s-a mărit după 48 de ore de testare (Fig.3).
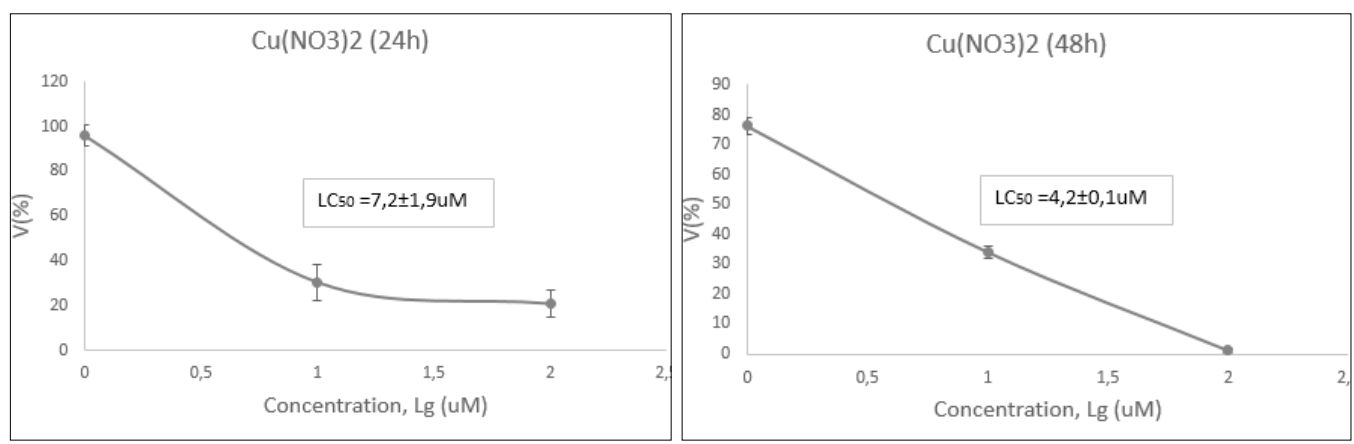

igura 3. Viabilitatea populaţiei Paramecium caudatum la acţiunea compusului $\mathrm{Cu}\left(\mathrm{NO}_{3}\right)_{2}$ după 24 şi 48 ore de acţiune

În baza rezultatelor obţinute s-a constatat că compușii CMT-67 și $\mathrm{Cu}\left(\mathrm{NO}_{3}\right)_{2}$, cu concentraţiile de 100, 10 și $1 \mu \mathrm{M}$ posedă o toxicitate semnificativă, manifestată prin reducerea substanţială a procentului de paramecii vii, după 24 și 48 ore de incubare, și posedă o concentraţie de inhibare semimaximală pentru CMT-67, LC ${ }_{50}$ este 10,0 și 5,1 și pentru $\mathrm{Cu}\left(\mathrm{NO}_{3}\right)_{2} \mathrm{LC}_{50}$ este 7,2 și 4,2 $\mu \mathrm{M}$.

\section{CONCLUZII}

1. La folosirea metodei descrise se micșorează timpul de efectuare a analizei de $\sim 2$ ori, se reduce cheltuielile de reagenți, se mărește sen- 
sibilitatea, precizitatea și reproductibilitatea metodei de determinare, în comparaţie cu prototipul. Aceasta permite de a aprecia mai precis toxicitatea substanţelor testate, se micșorează cheltuielile de reagenţi, crește productivitatea muncii cu un efect economic substanțial.

2. Procedeul propus conform invenţiei asigură accelerarea biotestării substanţelor în vederea stabilirii mai exacte a toxicităţii lor și relevarea dependenţei toxicităţii faţă de concentraţiile substanțelor studiate.

3. În urma examinării preparatelor $\mathrm{CMT}-67$ și $\mathrm{Cu}\left(\mathrm{NO}_{3}\right)_{2}$ s-a evidenţiat unele diferenţe statistice la astfel de caracteristici cum ar fi: închistarea ciliatelor, comportamentul de deplasare, lezarea peretelui celular după care survine moartea substantială a lor.

4. În urma analizei efectuate a fost stabilit că preparatele CMT-67 și $\mathrm{Cu}\left(\mathrm{NO}_{3}\right)_{2}$ sunt toxice pentru test-organismele P.caudatum.

5. S-a demonstrat că compusul coordinativ CMT-67 inhibă total creșterea și diviziunea infuzoriilor la concentrația de $100 \mu \mathrm{M}$, însoţită de formarea chisturilor celulare.

6. În diapazonul de concentraţii 1-100 $\mu \mathrm{M}$ au fost calculate valorile $\mathrm{LC}_{50}$ (concentraţia letala) pentru substanţele CMT-67 și $\mathrm{Cu}\left(\mathrm{NO}_{3}\right)_{2}$. Astfel, pentru CMT-67 $\mathrm{LC}_{50}=5,1 \pm 1,6 \mu \mathrm{M}$, iar pentru $\mathrm{Cu}\left(\mathrm{NO}_{3}\right)_{2}, \mathrm{LC}_{50}=4,2 \pm 0,1$ $\mu \mathrm{M}$, după 48 ore de testare. De aici rezultă că CMT-67 este mai puţin toxic faţă de $\mathrm{Cu}\left(\mathrm{NO}_{3}\right)_{2}$.

7. S-a demonstrat corelaţia dintre concentraţia substanţei și procentul parameciilor vii: cu cât concentraţia este mai mare (în cazul dat 100 $\mu \mathrm{M}) \mathrm{cu}$ atât procentul parameciilor vii este mai mic, și invers, cu cât concentraţia este mai mică $(1 \mu \mathrm{M})$ cu atât procentul parameciilor vii este mai mare.

\section{BIBLIOGRAFIE}

1. http://school-science.ru/4/1/1288

2. MILHAUD., G.E., et al. Les toxiques neurotropes Alfort E.N.V. , U.P. de Pharmacie et Toxicologie. 1995. 
3. REPETTO, G., DEL PESO, A., ZURITA, J.L.. Neutral red uptake assay for the estimation of cell viability/cytotoxicity. Nat Protoc 3: 1125-1131. (PDF Download Available).

4. TODERAȘ I., GULEA A., GUDUMAC V., ROȘCOV E., GARBUZ O.. "Metodă de apreciere a toxicităţii substanţelor chimice", Brevet de invenţie Nr. : S 2017 0067.,data: 2017.05.23. Institutul de Zoologie.

5. ВИНОХОАОВ А. О.. Научные основы биотестирования с использованием инфузорий. Аиссертация, 03.00.23. Санкт-Петербург. Биотехнология. 2007. 353 c.

6. КОКОВА, В. Непрерывное культивирование беспозвоночных. Новосибирск. «Наука» Сибирское отАеление, 1982, 168 с. 